Pesq. Vet. Bras. 37(11):1275-1280, novembro 2017 DOI: $10.1590 / \mathrm{S} 0100-736 \mathrm{X} 2017001100013$

\title{
Analysis of lower urinary tract disease of $\operatorname{dog} s^{1}$
}

\author{
Claudia Iveth Mendóza-López², Javier Del-Angel-Caraza ${ }^{2 *}$, Israel Alejandro \\ Quijano-Hernández ${ }^{2}$ and Marco Antonio Barbosa-Mireles ${ }^{2}$
}

\begin{abstract}
Mendóza-López C.I., Del-Angel-Caraza J., Quijano-Hernández I.A. \& Barbosa-Mireles M.A. 2017. Analysis of lower urinary tract disease of dogs. Pesquisa Veterinária Brasileira 37(11):1275-1280. Hospital Veterinario para Pequeñas Especies, Facultad de Medicina Veterinaria y Zootecnia, Universidad Autónoma del Estado de México, Jesús Carranza 203, Col. Universidad, CP 50130, Toluca, Mexico. E-mail: dlangel@uaemex.mx

Lower urinary tract diseases (LUTD) include different conditions that affect the urinary bladder, urethra and prostate. The objective of this study was to determine the frequency of different related diseases, to characterize the population affected, and to determine risk factors in dogs. The clinical cases were diagnosed with LUTD through physical examination, and clinical laboratory and imaging studies. Male dogs had a greater predisposition to present a LUTD. Dogs from 3 months to 18 years with a median of 8 years were affected, and the most affected breeds were Poodle, Labrador, German shepherd, Schnauzer, Cocker Spaniel and Chihuahua. The LUTD presented with the following frequencies: bacterial urinary tract infection $34.02 \%$; micturition disorders $22.68 \%$; urolithiasis $20.61 \%$; prostatic disease $14.43 \%$; traumatic problems $8.24 \%$. Sixty-seven per cent of the cases were specific diseases, such as uncomplicated and complicated bacterial urinary tract infections, urinary retention of neurologic origin and silica urolithiasis.
\end{abstract}

INDEX TERMS: Lower urinary tract disease, epidemiology, dog, urolithiasis, urinary tract infection, micturition disorders, prostate disease.

RESUMO.- [Análise de doenças do trato urinário inferior em cães.] Doenças do trato urinário inferior (DTUI) incluem várias condições clínicas que afetam a bexiga, próstata e uretra. 0 objetivo deste estudo foi determinar a frequência de diferentes doenças relacionadas, caracterizar a população afetada, e determinar os fatores de risco em cães. Os casos clínicos com DTUI foram diagnosticados através de exame físico, estudos laboratoriais e de imagem. Os cães machos apresentam uma maior predisposição para DTUI. Foram afectados cães com idades compreendidas entre os 3 meses a 18 anos, com uma mediana de oito anos, sendo as raças mais predispostas os Poodle, Labrador, Pastor Alemão, Schnauzer, Cocker Spaniel e Chihuahua. A etiologia DTUI apresentou as seguintes frequências: $34,02 \%$ foram originadas em infecção do trato urinário inferior; $22,68 \%$ em distúrbios miccionais; $20,61 \%$ em urolitíase; $14,43 \%$ em doença

\footnotetext{
${ }^{1}$ Received on July 24, 2015.

Accepted for publication on December 6, 2016.

${ }^{2}$ Hospital Veterinario para Pequeñas Especies, Facultad de Medicina Veterinaria y Zootecnia (FMVZ), Universidad Autónoma del Estado de México (UAEMex), Jesús Carranza 203, Col. Universidad, CP 50130, Toluca, Mexico. *Corresponding author: dlangel@uaemex.mx
}

prostática; $8,24 \%$ em problemas traumáticos. Sessenta e sete por cento dos casos de DTUI estavam associados a doenças específicas, tais como infecções bacterianas do trato urinário não complicadas e complicadas, retenção urinária neurogénica e urolitíase por sílica.

TERMOS DE INDEXAÇÃO: Doença do trato urinário inferior, epidemiologia, urolitíase, infecção urinária, distúrbios miccionais, doença prostática, cães.

\section{INTRODUCTION}

In dogs, lower urinary tract disease (LUTD) include various diseases that affect the bladder, urethra, and prostate. The most common clinical signs related to these diseases in dogs are hematuria, strangury, pollakiuria, urinary incontinence, or urine that burns the skin (Bartges 2004). However, none of these signs is indicative of a specific disease, such as bacterial urinary tract infection, urolithiasis, micturition disorders or prostate diseases.

In humans, there have been variations in the reported frequency of different diseases affecting the lower urinary tract from one population to another, and hence epidemiological data, such as geographical region, age, gender, breed, diet, and genetic predisposition, are considered as risk 
factors (Medina et al. 2004). However, there is little data regarding risk factors for LUTD in humans in Mexico.

In small animal veterinary medicine, few epidemiological studies have been published that have studied these pathologies. Bartges (2004) in USA reported that LUTD occurred more frequently in cats $(7.3 \%)$ than in dogs (3\%), in dogs the most common diseases were urinary tract infection (14\%) and urolithiasis (3\%). Inkelmann et al. (2012a) in Brazil studied necropsied dogs with lesion in the urinary tract system, and reported $26.2 \%$ lesions of the lower urinary tract and the nonspecific inflammatory lesions, obstructive and acquired anatomic alteration at the most common lesions. In other scientific reports, each of the LUTD has been studied independently.

In Mexico, LUTD in dogs occur regularly in daily practice, but there are no scientific reports on the characteristics of the dog population affected or their risk factors. The aim of this study was to determine the frequency of different LUTD in dogs, to characterize the population, and to determine the risk factors in dogs that were treated by the medical services in our hospital.

\section{MATERIALS AND METHODS}

Period study and location. This study was conducted between August 2012 to January 2014; at the Hospital Veterinario para Pequeñas Especies (Small Animal Teaching Hospital) of the Veterinary Faculty of Universidad Autonoma del Estado de Mexico, in

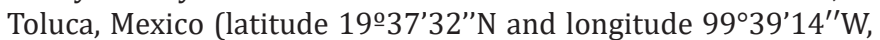
with an altitude of 2640 meters above sea level, with a subtropical climate).

Case selection. Cases included dogs that were consulted for the first time with related clinical signs of a LUTD, such as hematuria, strangury, pollakiuria, or urinary incontinence. To establish a definitive diagnosis, different laboratory studies were conducted, including complete blood count, biochemical profile, and urinalysis, as well as imaging studies, such as radiology and ultrasonography of the urinary tract. In almost all patients, the urine samples were obtained by cystocentesis except in those animals that showed rupture of the urinary bladder. Chronic cases of LUTD were discarded in order to rule out a late diagnosis or therapeutic errors.

Variables including age, gender, breed, diagnosis, and the gonadal state in male dogs with some prostatic disease or urinary incontinence in female dogs were studied.

Bacterial urinary tract infection (BUTI) was diagnosed in the light of clinical signs, the presence of other urinary or systemic diseases, and complete urinalysis (Weese et al. 2011), as well as when microscopic examination of urinary sediment showed $>5$ erythrocytes and/or leukocytes (pyuria) per field (400x), with the presence of bacteria and epithelial cells considering an active inflammation of septic origin (Pressler et al. 2003). BUTI cases with other comorbidities were considered as complicated BUTI, and clinical cases with no association with other diseases were considered as single or uncomplicated BUTI. Urinary culture was considered only in cases in which the infection did not respond to initial antibiotic therapy, which were considered to be recurrent BUTI (relapses, reinfections, or superinfections).

Urolithiasis was diagnosed once uroliths were located by radiography and/or ultrasonography, and these were surgically removed or by urohidropropulsion, all uroliths were analyzed with a physicochemical quantitative method, stereoscopic microscopy (Stemi DV4 Stereo Microscope, Zeiss-USA), and infrared spectroscopy (FT-IR Spectrum two, Perkin Elmer-USA) in order to deter- mine the mineral composition (Del-Angel-Caraza et al. 2010).

For micturition disorders, cases of urinary incontinence were diagnosed based on the urine leakage between micturition periods and the presence of urine that burns the skin in the perineal region. Urinary retention cases were diagnosed by measuring the post-void residual urine above $0.4 \mathrm{ml} \mathrm{kg}^{-1}$ (Fischer \& Lane 2007) and in both cases a detailed neurological exam and the gonadal state relation.

For prostate diseases, a combination of various techniques, such as rectal palpation, radiology, ultrasonography, urinalysis, and aspiration cytology, were used.

Statistical analysis. We used descriptive statistics in order to determine relationships between LUTD and the analyzed variables. Values of $X i^{2}$ and OR with a 95\% confidence were calculated.

\section{RESULTS}

During the study period, 97 dogs were diagnosed with any LUTD; $74.22 \%(n=72)$ were males and $25.78 \%(n=25)$ females, with a male-female ratio of 2.8:1, and an age range from 3 months to 18 years with a median age of 8 years. The control group included 338 dogs (174 males and 164 females) with diagnoses other than LUTD.

There was a significant association with the male gender and LUTD (OR 2.71, IC 1.64-4.78, p<0.05).

Of the affected animals, $82.47 \%(n=80)$ were purebred dogs, and the rest were crossbreeds. The most common breeds affected were Poodle $13.75 \%$ (OR 0.98, CI 0.481.98), Labrador $9.27 \%$ (OR 1.68, IC0.82-3.44), German Shepherd $8.24 \%$ (OR 1.88, CI 0.78-4.53), Schnauzer (6.18\%) (OR 0.95, CI 0.42-2.15), Cocker Spaniel (5.15\%) (OR 1.03, CI 0.43-2.47), and Chihuahua (5.15\%) (OR 1.03, CI 0.432.47). However, no breed predisposition was observed towards any of these conditions ( $p>0.05)$. Other breeds were merely represented.

The most frequently observed signs included hematuria and urinary retention $(19.58 \%$ each), pollakiuria $(6.17 \%)$, strangury $(5.15 \%)$, urinary incontinence $(2.06 \%)$, depression $(2.06 \%)$, and weakness in lower limbs, abdominal pain, and urinary fistula with $1.03 \%$ each. However, $43.29 \%$ of the dogs did not show any clinical signs of LUTD and were diagnosed incidentally during routine tests or had extra-urinary problems.

The LUTD were presented in the following order of frequency: BUTI, micturition disorders (anatomical alteration and incompetence of the urethral sphincter), urolithiasis, prostate diseases (prostatic hyperplasia and prostatic cysts), and traumatic problems (traumatic cystitis, and rupture of the bladder and/or urethra). Some dogs had one or more conditions simultaneously (Table 1).

BUTI was the most frequent LUTD and presented in $34.02 \%(n=33)$ of clinical cases $(63.63 \%(n=21)$ males and $36.36 \%(n=12)$ females). Statistically, there was no evidence of predisposition to present BUTI by gender (OR $1.3, \mathrm{CI} 0.65-2.87, \mathrm{p}>0.05)$. Dogs diseased were aged from 3 months to 18 years (median age: 8 years). Purebred dogs accounted for $84.84 \%(n=28)$ of cases, with the most frequent being Poodle (17.85\%; $n=5)$, Chihuahua (17.85\%; $n=5)$, and Labrador (17.85\%; $n=5)$. Total affected animals showed an acute BUTI because there was no history of recurrent infection. Of the BUTI cases, $54.55 \%(n=18)$ were 
Table 1. Distribution of the dog studied in the different LUTD groups

\begin{tabular}{|c|c|c|c|c|c|}
\hline Pathologies & Number (\%) & Females (\%) & Males (\%) & Median age (years) & Significant findings \\
\hline BUTI* & $33(34.02)$ & $12(36.36)$ & $21(63.63)$ & 8 & $\begin{array}{l}\text { - Uncomplicated infections } 54.55 \% \\
\text { - Complicated infections } 45.45 \%\end{array}$ \\
\hline Micturition disorders & $22(22.68)$ & $9(40.90)$ & $13(59.09)$ & 7 & $\begin{array}{l}\text { - Urinary retention } 90.90 \% \\
\text { - Urinary incontinence } 9.09 \%\end{array}$ \\
\hline Urolithiasis & $20(20.61)$ & $4(20.00)$ & $16(80.00)$ & 9 & $\begin{array}{l}\text { - Silicate } 55 \% \\
\text { - Struvite } 30 \\
\text { - Calcium oxalate } 15 \% \\
\text { - Male with urethral obstruction } 93.75 \%\end{array}$ \\
\hline Prostate disease & $14(14.43)$ & $-(-)$ & $14(100.00)$ & 9 & $\begin{array}{l}\text { - Prostatic hyperplasia } 100 \% \\
\text { - Prostatic cysts } 14.28 \%\end{array}$ \\
\hline Trauma & $8(8.24)$ & $0(0)$ & $8(100.00)$ & 5 & $\begin{array}{l}\text { - Rupture of the urinary tract } 37.50 \% \\
\text { - Traumatic cystitis } 62.50 \%\end{array}$ \\
\hline
\end{tabular}

* Bacterial urinary tract infection.

diagnosed as acute BUTI, and $45.45 \%(n=15)$ were considered complicated BUTI associated with other LUTD, including urolithiasis $(n=3)$, prostatic disease $(n=3)$, and micturition disorders $(n=4)$, as well as some systemic diseases, such as hyperadrenocorticism, diabetes mellitus, and pyometra with one case each. Only two cases were associated with a previous urethral catheter placement.

Micturition disorders (MD) were the second most common group of diseases, with $22.68 \%(n=22)$ neurological and non-neurological causes of all BUTI. Micturition disorders due to neurological causes occurred in $90.90 \%(n=20)$ of patients, of which $65.00 \%(n=13)$ were male, with a male-female ratio of 1.8:1. However, statistically there was no gender predisposition towards presenting a MD due to neurological causes (OR 1.4, CI 0.56-3.71, p>0.05). With an age range of 1-13 years (median age: 7 years), $68 \%$ of the cases occurred in purebred animals, and the most frequent breeds were Poodle (33.33\%; $n=5)$ and Dachshund (20\%; $n=3$ ), but crossbreeds accounted for $30 \%$ of the cases. The clinical signs associated with neurological MD were urinary retention associated with different injuries affecting the upper motor neurons. As for non-neurological MD causes, these were found in $9.09 \%(n=2)$, where females with urinary incontinence attributed urethral sphincter incompetence in a 10-year-old, neutered crossbreed, and one case of ectopic ureter in a 3-month-old Poodle.

Urolithiasis represented $20.61 \%(n=20)$ of cases, and from these, $80 \%(n=16)$ were male, but there was no statistical predisposition by gender (OR 1.5, CI 0.44-5.00, $\mathrm{p}>0.05)$. The age range was between 3 and 15 years with a median of 9 years. Urolithiasis was found in purebreds in $95 \%(n=19)$ of cases, and the most common breed was the German Shepherd (20\%). According to the chemical composition of uroliths, the clinical cases were distributed in urolithiasis by silicate $(55 \%)$, struvite $(30 \%)$, and calcium oxalate (15\%). Of the males, 15 of the $16(93.75 \%)$ animals had urethral obstruction that was caudal to the penile bone due to silica or calcium oxalate uroliths (Fig.1).

Prostate diseases occurred in $14.43 \%(n=14)$, and two pathologies were found: prostatic hyperplasia and prostatic cysts. Prostatic hyperplasia occurred in all cases, with an age range of 4-16 years (median age: 9 years), and $64.28 \%$ $(n=9)$ were purebred dogs and $35.71 \%(n=5)$ crossbred dogs. There was no predisposition regarding breed (OR

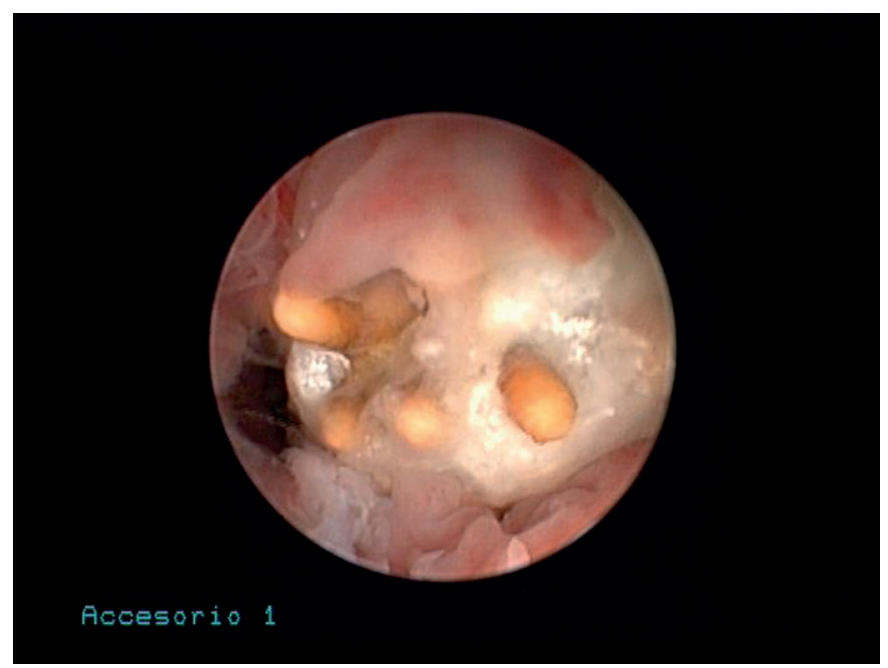

Fig.1. Endoscopic imaging of uroliths in the urethra of a male dog (Image obtained with a $2.7 \mathrm{~mm}$ HOPSKINS $^{\circledR}$ telescope $30^{\circ}$ and Telecam SL II, Karl Storz Endoskope-Germany). Note the presence of mucus with attached crystals around the urolith. The hyperplasia of the urethral mucosa suggests chronicity of the obstruction. After removing the urolith, it showed a Jackstone shape and a $4 \mathrm{~mm}$ diameter. The mineral composition was determined by infrared spectroscopy as a silica urolith. The crystals attached to the mucus were struvite, which is commonly related to a bacterial chronic urinary tract infection by urease-positive bacteria and the histopathological evaluation of urethra confirmed a proliferative urethritis.

0.30 , CI $0.08-1.06, \mathrm{p}>0.05)$. Prostatic cysts occurred in only $2(14.28 \%)$ cases, simultaneously with hyperplasia in an 11-year-old Rottweiler and a 12-year-old crossbred dog. None of the clinical cases were castrated.

Problems caused by trauma occurred in $8.24 \%(n=8)$, all of which were male. Pathologies were ruptured urethra, bladder rupture, and hemorrhagic cystitis. Urethral rupture occurred in three dogs of (3-month-old Mastiff, 5-year-old Rottweiler, and a 16-year-old Poodle with simultaneous bladder rupture). Traumatic cystitis was present in five cases, with an age range from 3 months to 10 years (median age: 5 years).

\section{DISCUSSION}

In our study, we observed a predisposition of males to present some LUTD, with dogs commonly around 8 years old, 
and without breed predisposition. In both genders, hematuria and urinary retention were the most frequent clinical signs of this pathology.

In our study, we did not observe a predisposition by gender to present a BUTI. In the clinical cases of this pathology, hematuria and urinary retention were the most common clinical signs.

The most frequent pathology observed was BUTI (34.02\%). Subclinical bacteriuria or silent BUTI has been reported with frequencies of $95 \%$ by other authors (McGuire et al. 2002, Seguin et al. 2003); however, these cases were excluded from this study because the approach was starting clinical signs of urinary tract flow. Some reports have shown that urinary tract infections are more common in females, which is attributed to anatomical features, such as a shorter urethra, and urethral papilla on the floor of the vagina where there is normal resident flora (Ling et al. 2001). In this study, BUTI was most frequently observed in males - related to the presence of other diseases - as a result of alterations in the defense mechanisms of the urinary tract, such as normal micturition, storage, and proper emptying of the bladder; antimicrobial properties, such as urine osmolality, urinary $\mathrm{pH}$, and concentration of ions; the integrity of the mucosal defense barrier, glycosaminoglycan layer, anatomical barriers, such as internal urethral sphincter, and closure of ureterovesical junctions with the pressure generated within the fill urine bladder, urethral length and finally systemic or local immunocompetence providing bacterial colonization of urinary tract epithelium, similar results was described by Inkelmann et al. (2012a). The mean age of in these animals was 8 years, which is consistent with previous reports (Ling et al. 2001, Cohn et al. 2003). This condition is commonly present in old animals due to the presence of other diseases that alter the defense mechanisms of the urinary tract.

Uncomplicated BUTI may be present in dogs that are considered healthy with a normal physiology and anatomy of the urinary tract (Weese et al. 2011). The presence of significant comorbidities, such as diabetes mellitus, hyperadrenocorticism, chronic renal disease, prostatic disease, (Bailiff et al. 2008), anatomic abnormalities of the urinary and reproductive tracts, or presentation of three or more episodes of infection per year, refer to a complicated or recurrent BUTI (Weese et al. 2011). In our study, 45.45\% of the cases presented a complicated BUTI associated with other urinary or systemic comorbidities, including prostate disease, micturition disorder, or urolithiasis, as well as systemic diseases, such as hypothyroidism, diabetes mellitus, pyometra, and urethral catheter placement. We did not perform any urine cultures because we had no cases of recurrent BUTI, such as relapses, reinfections, or superinfections, possibly because patients were submitted for consultation to our hospital when clinical signs began, and hence were considered acute cases.

Normal micturition is defined as alternating phases of storage and emptying of the urinary bladder. Micturition disorders present as two groups of problems that affect the process of normal micturition: urinary retention (alteration in emptying of the urinary bladder) and urinary incontinence (inability to hold urine in the bladder between micturition periods). In both, the source of the injury may have a neurological or non-neurological origin (Labato 2005). In our study, MD were present in $22.68 \%(n=22)$ of the studied population. Urinary retention $(90.90 \%)$ manifests primarily with paradoxical (or overflow) incontinence and/or residual urine post-micturition volume $>0.4 \mathrm{ml}$ $\mathrm{kg}^{-1}$ (Labato 2005). Pathophysiologically, the cases were attributed to spinal injuries associated with alteration of upper or lower motor neurons caused by damage to the spinal cord or peripheral nerves, which as a side-effect can cause detrusor muscle arreflexia and arreflexia or hypertonia of the internal urethral sphincter, or urethral-detrusor dyssynergia with a chronic or acute presentation. The majority of the animals were male, older, and crossbred, which agrees with the results previously reported by Bubenik \& Hosgood (2008) who associated this problem with degenerative diseases of the spine associated with mixtures of predisposed breeds.

Non-neurological causes or MD are those that occur with structural or functional disorders, or congenital diseases that generate an alteration in the process of normal micturition. In the population studied, only two cases (9.09\%) with urinary incontinence were presented, one associated with urethral sphincter incompetence and the other with an ectopic ureter, which are the pathologies that are the most frequently related causes of urinary incontinence in females (Hoelzler \& Thrusfield 2004). The incompetence of the urethral sphincter has been attributed to a functional weakness of the internal urethral sphincter, especially in females with estrogen deficiency. It is estimated that over $20 \%$ of spayed females are affected (Holt \& Thrusfield 1993); however, there are reports that less than $1 \%$ are intact female older dogs had a minor tone of the urethral sphincter associated with a decreasing response to alpha-adrenergic urethral receptors (Fischer \& Lane 2007). In our study, our only case involved a spayed 10 -year-old female dog. The other incontinent female dog was a 3 -month-old Poodle with an ectopic ureter voiding to the vagina, which is a congenital anatomic abnormality, wherein one or both ureters usually end in the vagina instead of flowing into the bladder trigone and causes urinary incontinence. The incidence of this disease has been estimated as $0.016 \%$, considering the Poodle breed like increased risk for this disease (Hayes 1994). In general, urinary incontinence related to urethral sphincter incompetence is the most common MD associated with an early castration. In our results, this disease was uncommon in the population studied, and the explanation for this finding may be that early sterilization is not a routine practice in our geographic area, unlike the protocols in other countries, such as the USA, Canada, or some countries from Europe.

Urolithiasis was the third most frequent pathology in our study $(20.16 \%)$. Uroliths were more likely to be found in males, in agreement with reports by Lulich et al. (1993) and Inkelmann et al. (2012b), which can be attributed to the anatomical characteristics of the male urethra that favors the permanence of small uroliths, unlike females who can expel some small uroliths during urination, but both 
sexes are equally prone to form uroliths. In our study, we found that $55 \%$ of the uroliths were silicate, followed by struvite and calcium oxalate. Silicate and calcium oxalate uroliths are generally small, and so the females can expel them more easily. In our study, $93.75 \%$ of males with urolithiasis had urethral obstruction.

The frequency of presentation of the different types of uroliths differs from previously published data in Mexico by Del Angel-Caraza et al. (2010) who reported struvite in $38 \%$ of cases as the most common uroliths, followed by calcium oxalate (26\%) and silicate (13\%). Other studies in different geographic areas of North America, Europe, and Brazil have reported calcium oxalate uroliths as being the most common, followed by struvite and purine, and silicate uroliths as having a frequency of $<1 \%$ (Osborne et al. 2009, Oyafuso et al. 2010, Vrabelova et al. 2011). Results of our previous studies (Del Angel-Caraza et al. 2010) suggest that the high frequency of silicate uroliths in dogs of Mexico is associated with the geographical area. For 5 years, our hospital has been a referral center for the analysis of uroliths from different animal species in Mexico, and it is common to find that silicate uroliths are present in animal populations inhabiting the Trans-Mexican neovolcanic axis, extending transversely from the Pacific Ocean to the Gulf of Mexico. It is feasible that the water in the aquifer mantles of the region contains high levels of silicates, and settlements in this area supply their water consumption from aquifers (Del-Angel-Caraza et al. 2010). This phenomenon has been considered as a risk factor for silicate urolithiasis for dogs in Japan (Tasaki et al. 2013). Because the formation of this kind of uroliths in dogs requires a constant intake of silica in the diet or water, have also been considered risk factors in affected animals.

The second most frequent type was struvite uroliths. Pathophysiologically, such mineral precipitates are found in the presence of oversaturated urine with phosphate, magnesium, and ammonium in dogs, especially related to a BUTI by urease-positive bacteria, such as Staphylococcus, Streptococcus and Proteus spp., and so females are primarily affected (Osborne et al. 2009).

Calcium oxalate was the third type of mineral present in our study. In Brazil, it has been reported as the second most common mineral (Oyafuso et al. 2010), in contrast to other studies where calcium oxalate uroliths were most frequent in comparison to struvite (Houston et al. 2004, Vrabelova et al. 2011). These differences in the findings of Latin countries are possibly due to demographic factors, nutritional changes, racial preferences, and perhaps a lack of protocols to dissolve struvite uroliths in the clinic. The pathophysiological mechanisms of calcium oxalate depends on the presence of hyperoxaluria and hypercalciuria, and are usually the idiopathic type or related to hyperadrenocorticism and chronic metabolic acidosis associated with the formation of this type of urolith (Osborne et al. 2009). In mammals, Oxalobacter forgimenes in the gastrointestinal tract has been identified, which is a bacteria that degrades oxalate for energy, and its presence has been suggested to play an important role in preventing formation of calcium oxalate uroliths in dogs (Gnanandarajah et al. 2012).
Prostate diseases were present in $14.43 \%$, and prostatic hyperplasia was found in all clinical cases studied. Prostatic hyperplasia is a normal clinical condition that includes an increase in the cell number and an increase in the size of these due to progressive changes related to age and testosterone exposure in dogs (Smith 2008). The median age was 9 years, agreeing with those reported by Gobello \& Corrada (2002). Prostatic cysts were found in only two animals, simultaneously with prostatic hyperplasia. Black et al. (1998) reported prevalence of $14 \%$, as well as in relation to prostatic hyperplasia, which is consistent with our results. None of the animals studied was castrated, which is considered as a factor in the development of prostatic hyperplasia because they were exposed to hormonal stimulation. Physiologically, the dogs exhibit a progressive enlargement of the prostate after puberty related to exposure to increased testosterone concentrations. In prostatic hyperplasia, there is an alteration in the relationship between estrogen and androgens. Estrogens increase the chance of developing hyperplasia as it increases the number of androgen receptors. Also, this size increase is related to an overproduction of the dihydrotestosterone metabolite, which is the main stimulator of prostatic hyperplasia (Smith 2008).

Problems due to trauma represented 8.24\%. These alterations are often generated by lesions in the musculoskeletal system, especially fractures of the femur or pelvis, and the abdominal cavity affecting the walls of the urethra or bladder, including ruptures. In our study, hemorrhagic cystitis, and vesical or urethral rupture were the most common diagnoses. Most cases were present in animals hit by a car. Anderson et al. (2006) reported this type of injury as the most common cause of rupture of the urethra. Urethral injury most commonly occurs in male dogs and cats, in part because the length of the urethra, and a lesser ability to relax, and hence the urethra is more prone to clogging, laceration, and transection (Selcer 1982). In the case of the bladder, rupture mechanisms include direct penetration of fractured fragments or a sudden increase in intravesical pressure; it is more common in males because the lesser urethra compliance favors the increase of intravesical pressure (Thornhill \& Cechner 1981). We had an interesting case of necrosis of the pelvic urethra by an entrapment of the urethra in a fractured pubis in a puppy; a similar case has been reported by Messmer et al. (2001). Other possible causes of urinary bladder or urethral injury may be the urethral catheter placement, bite wounds, pelvic fractures, gunshot wounds, bone penis fractures, and obstruction by urinary calculi (Gannon \& Moses 2002), plus iatrogenic causes, such as cystocentesis or traumatic urethral catheter placement (Anderson et al. 2006), urethrocystoscopy, prostatectomy, cryptorchidectomy (Schulz et al. 1996) or perianal hernia corrections (Sereda et al. 2002). In our study, we found only one case of secondary urethral obstruction due to correction of a perianal hernia.

\section{CONCLUSIONS}

We conclude that the more frequent LUTD affecting the $67 \%$ of dog population studied were specific diseases such as: uncomplicated and complicated bacterial urinary tract 
infection, urinary retention - of neurologic origin due to spinal cord disease - and silica urolithiasis.

As in LUTD pathologies studied, elder males were the most affected, with the exception of traumatic problems encountered in young adult male dogs.

The results of this work set the basis for establishing protocols for early diagnosis of LUTD in dogs.

Further studies are needed; but initially we suggest to perform annual valorations of the lower urinary tract at the dogs starting at 6 years old, including hematological and biochemical profiles, urianalysis, and imaging studies, as well as prostate palpation; and measuring the volume of residual urine post-micturition when there are clinical findings of neurological disease.

Acknowledgements.- The authors gratefully acknowledge the medical personnel of the Hospital Veterinario para Pequeñas Especies de la Facultad de Medicina Veterinaria y Zootecnia de la Universdad Autónoma del Estado de México. Claudia Iveth Mendóza-López held a scholarship from the Consejo Nacional de Ciencia y Tecnología (CONACyT), México.

Conflict of interests.- The authors declare no conflicts of interest

\section{REFERENCES}

Anderson R.B., Aronson L.R., Drobatz K.J. \& Atilla A. 2006. Prognosis factors for successful outcome following urethral rupture in dogs and cats. J. Am. Anim. Hosp. Assoc. 42:136-146.

Bailiff N.L., Westropp J.L., Nelson R.W., Sykes J.E., Owens S.D. \& Kass P.H. 2008. Evaluation of urine specific gravity and urine sediment as risk factors for urinary tract infections in cats. Vet. Clin. Pathol. 37:317-322.

Bartges J.W. 2004. Diagnosis of urinary infections. Vet. Clin.-Small. Anim. 3:4923-933.

Black G.M., Ling G.V., Nyland T.G. \& Baker T. 1998. Prevalence of prostatic cysts in adult, large-breed dogs. J. Am. Anim. Hosp. Assoc. 34:177-80.

Bubenik L. \& Hosgood G. 2008. Urinary tract infection in dogs with thoracolumbar intervertebral disc herniation and urinary bladder dysfunction managed by manual expression, indwelling catheterization or intermittent catheterization. Vet. Surg. 37:791-800.

Cohn L.A., Gary A.T., Fales W.H. \& Madsen R.W. 2003. Trends in fluoroquinolone resistance of bacteria isolated from canine urinary tracts. J. Vet. Diagn. Invest. 15:338-343.

Del Angel-Caraza J., Diez-Prieto I., Perez-García C.C. \& García-Rodríguez M.B. 2010. Composition of lower urinary tract stones in canines in México city. Urol. Res. 38:201-204.

Fischer J. \& Lane I. 2007. Incontinence and urine retention, p.26-40. In: Brainbridge J. \& Elliott J. (Eds), Manual of Canine and Feline Nephrology and Urology. 2nd ed. British Small Animal Veterinary Association, Gloucester, UK.

Gannon K.M. \& Moses L. 2002. Uroabdomen in dog and cat. Compend. Contin. Educ. Pract. Vet. 24:604-612.

Gnanandarajah J.S., Abrahantee J.E., Lulich J.P. \& Murtaugh M.P. 2012. Presence of Oxalobacter formigenes in the intestinal tract is associated with the absence of calcium oxalate urolith formation in dogs. Urol. Res. 40:467-473.

Gobello C. \& Corrada Y. 2002. Noninfectious prostatic diseases in dogs. Compend. Contin. Educ. Pract. Vet. 24:99-107.

Hayes H.M. 1994. Breed associations of canine ectopic ureter: a study of 217 female cases. J. Small Anim. Pract. 25:501-504.

Hoelzler M.G. \& Lidbetter D.A. 2004. Surgical management or urinary incontinence. Vet. Clin. N. Am., Small Anim. 34:1055-1057.

Holt P.E. \& Thrusfield M.V. 1993. Association between breed, size, neutering and docking, and acquired urinary incontinence due to incompetence or the urethral sphincter mechanism. Vet. Rec. 133:177-180.
Houston D.M., Moore A.E., Favrin M.G. \& Hoff B. 2004. Canine urolithiasis: a look at over 16,000 urolith submissions to the Canadian Veterinary Urolith Centre from February 1998 to April 2003. Can. Vet. J. 45:225230.

Inkelmann M.A., Kommers G.D., Trost M.E., Barros C.S.L., Fighera R.A., Irigoyen L.F. \& Silveira I.P. 2012a. Lesions of the urinary systems in 1.063 dogs. Pesq. Vet. Bras. 32:761-771.

Inkelmann M.A., Kommers G.D., Trost M.E., Barros C.S.L., Fighera R.A., Irigoyen L.F. \& Silveira I.P. 2012b. Urolithiasis in 76 dogs. Pesq. Vet. Bras. 32:247-253.

Labato M.A. 2005. Micturition disorders, p.105-109. In: Ettinger S.J. \& Feldman E. (Eds), Textbook of Veterinary Internal Medicine. 2nd ed. Elsevier, Missouri, USA.

Ling G.V., Norris C.R., Franti C.E., Elsele P.H., Johnson D.L., Ruby A.L. \& Jang S.S. 2001. Interrelations of organism prevalence, specimen collection method, and host age, sex and breed among 8354 canine urinary tract infections (1969-1995). J. Vet. Intern. Med. 15:341-347.

Lulich J.P., Osborne C.A., Unger L.K., Samelson L.L., Koehler L.A. \& Bird K.A. 1993. Nonsurgical removal of urocystoliths by voiding urohydropropulsion. J. Am. Vet. Med. Assoc. 203:660-663.

McGuire N.C., Schulman R., Ridgway M.D. \& Bollero G. 2002. Detection of occult urinary tract infections in dogs with diabetes mellitus. J. Am. Anim. Hosp. Assoc. 38:541-544.

Medina-Escobedo M., Medina-Escobedo C. \& Martin-Soberanis G. 2004. Frecuencia de las enfermedades del sistema urinario en niños atendidos en un Hospital General en Yucatán, México. Boln Med. Hosp. Infant. Mex. 61:482-488.

Messmer M., Rytz U. \& Spreng D. 2001. Urethral entrapment following pelvic fracture fixation in a dog. J. Small Anim. Pract. 42:341-344.

Osborne C.A., Lulich J.P., Kruger J.M., Ulrich L.K. \& Koehler L.A. 2009. Analysis of 451.891 canine uroliths, feline uroliths, and urethral plugs from 1981 to 2007: Perspective from the Minnesota Urolith Center. Vet. Clin. N. Am., Small Anim. Pract. 39:183-197.

Oyafuso M.K., Kogika M.M., Waki M.F., Prosser C.S., Cavalcante C.Z. \& Fortunato Wirthl V.A.B., 2010. Urolitíase em cães: avaliação quantitativa da composição mineral de 156 urólitos. Ciencia Rural 40:102-108.

Pressler B.M., Vaden S.L., Lane I.F., Cowgill L.D. \& Dye J.A. 2003. Candida spp. urinary tract infections in 13 dogs and seven cats: predisposing factors, treatment, and outcome. J. Am. Anim. Hosp. Assoc. 39:263-70.

Schulz K.S., Waldron D.R., Smith M.M., Henderson R.A. \& Howe L.M. 1996. Inadvertent prostatectomy as a complication of cryptorchidectomy in four dogs. J. Am. Anim. Hosp. Assoc. 32:211-214.

Seguin M.A., Vaden S.L., Altier C., Stone E. \& Levine J.F. 2003. Persistent urinary tract infections and reinfections in 100 dogs (1989-1999). J. Vet. Intern. Med. 17:622-631.

Selcer B.A. 1982. Urinary tract trauma associated whit pelvic trauma. J. Am. Anim. Hosp. Assoc. 19:785-793.

Sereda C., Fowler D. \& Shmon C. 2002. Iatrogenic proximal urethral obstruction after inadvertent prostatectomy during bilateral perineal herniorrhaphy in a dog. Can. Vet. J. 43:288-290.

Smith J. 2008. Canine prostatic disease: A review of anatomy, pathology, diagnosis and treatment. Theriogenology 70:375-383.

Tasaki Y., Ito G., Miura N., Tanaka M. \& Momoi Y. 2013. Predisposing cause and prevention of canine silica urolithiasis. J. Pet Anim. Nutr. 16:61-66.

Thornhill J.A. \& Cechner P.E. 1981. Traumatic injuries to the kidney, ureter, bladder and urethra. Vet. Clin. N. Am., Small Anim. Pract. 1:157-169.

Vrabelova D., Silvestrini P., Ciudad J., Gimenez J.C., Ballesteros M., Puig P. \& Ruiz de Gopegui R. 2011. Analysis of 2735 canine uroliths in Spain and Portugal. A retrospective study: 2004-2006. Res. Vet. Sci. 91:208-211.

Weese J.S., Blondeau J.M., Boothe D., Breitschwerdt E.B., Guardabassi L., Hillier A., Lloyd D.H., Papich M.G., Rankin S.C., Turnidge J.D. \& Sykes J.E. 2011. Antimicrobial use guidelines for treatment of urinary tract disease in dogs and cats: antimicrobial guidelines working group of the international society for companion animal infection disease. Vet. Med. Int. 63768. DOI: $10.4061 / 2011 / 263768$. 